\title{
ETNOGRAFI KOMUNIKASI PADA UPACARA PERNIKAHAN BETAWI
}

\author{
Asaas Putra ${ }^{1}$, Shabrina Shanaz ${ }^{2}$ \\ Fakultas Komunikasi dan Bisnis, Program Studi Ilmu Komunikasi, Universitas Telkom, Bandung \\ Naskah diterima tanggal 10 Juli, direvisi tanggal 21 Agustus, disetujui tanggal 1 September
}

\begin{abstract}
Abstrak. Indonesia merupakan negara ketiga dengan predikat penduduk terbanyak, dengan memiliki daerah kepulauan yang sangat luas menjadikan Indonesia memiliki keanekaragamaan budaya dari setiap masing-masing daerah. Lebih dari 300 bahasa daerah di miliki oleh Indonesia dan menjadikan Indonesia unggul akan budaya di antara negara lain. Budaya Indonesia sudah banyak yang mendunia mulai dari seni tarinya, kerajinan, makanan, hingga batik yang akhirnya menjadi simbol dari ciri khas Indonesia. Berbicara tentang budaya Indonesia, maka upacara adat istiadat pada pernikahan juga suatu bagian dari budaya Indonesia. Dalam upacara adat pernikahan tanpa kita sadari banyak sekali simbol atau makna-makna dari setiap bagian pada upacara tersebut, namun untuk menginterpretasikan simbol atau makna-makna dari setiap bagian upacara kita harus mencari tahunya dengan cara melakukan komunikasi secara langsung dengan ahlinya dan melihat langsung dalam upacara tersebut. Upacara adat pada pernikahan terdapat banyak sekali makna dan simbol serta perilaku dari setiap pelakon yang memerankan pada upacara adat pernikahan. Dan makna, simbol, serta perilaku adalah sebuah bagian dari ilmu komunikasi. Perilaku komunikasi merupakan tindakan yang di tafsirkan seseorang dalam bentuk komunikasi baik itu verbal maupun non verbal.
\end{abstract}

\section{Kata kunci: Perilaku Komunikasi, Budaya, Makna, Asimilasi.}

Abstract. Indonesia is the third country with the largest population predicate, by having a very wide area of the islands makes Indonesia has diversity culture of each respective region. More than 300 local language owned by Indonesia and makes Indonesia superior culture among of the other countries. Many of Indonesia culture already worldwide, start from traditional dance, handicraft, food, until batik which eventually became the symbol of the hallmark of Indonesia. Talk about the culture of Indonesia, then the wedding ceremonies are also a part of Indonesian culture. In the ceremony of Indonesia wedding without we realized it, there is many more symbol or meaning from each part on the ceremony, but for interpretation the symbol or meaning from each part of the ceremony we should finding with doing some communication face to face with the master and see directly into the ceremony. In the ceremony of Indonesia wedding there is many more symbols and meaning and behavior from every actor who played at the wedding ceremonies. And symbols, meaning, and behavior is a part of communication science. Communication behavior constitute action that someone for interpreted in the form of communication both verbal and non-verbal.

Keywords: Communication Behavior, Culture, Meaning, Asimilation. 


\section{PENDAHULUAN}

Indonesia adalah negara ketiga dengan predikat penduduk terbanyak, yang memiliki daerah kepulauan yang sangat luas. Sehingga Indonesia memiliki keanekaragamaan budaya, dari masing-masing daerah. Badan Pengembangan Pembinaan Bahasa, Kementerian Pendidikan Kebudayaan menyatakan, berdasarkan data terakhir, Indonesia memiliki 652 bahasa daerah (Liputan6.com, 2018) dan ini menjadikan Indonesia memiliki keanekaragaman budaya dibandingkan dengan negara lain. Budaya Indonesia sudah banyak yang mendunia mulai dari seni tarinya, kerajinan, makanan, hingga batik yang akhirnya menjadi simbol dari ciri khas Indonesia.

Budaya memiliki banyak turunannya, salah satunya adalah upacara pernikahan. Upacara pernikahan memiliki adat istiadat dan pakem tertentu. Dalam upacara adat pernikahan banyak sekali simbol atau makna-makna yang terkandung didalamnya, untuk menginterpretasikan simbol atau makna-makna dari setiap bagian upacara, haruslah dilakukan pengamatan dan observasi secara langsung, termasuk didalamnya melakukan wawancara dengan tokoh adat.

Putra (2015) mengatakan manusia merupakan makhluk sosial yang memiliki kecenderungan untuk berkelompok (gemainschaft) dan saling mengikat. Setiap komunitas manusia mempunyai norma tersendiri dalam mengatur hubungan antarpribadi. Norma tersebut bisa berangkat dari norma budaya ataupun norma agama. Upacara adat pada pernikahan terdapat banyak sekali makna dan simbol juga perilaku dari setiap pelakunya. Makna, simbol, serta perilaku adalah sebuah bagian dari ilmu komunikasi, Perilaku komunikasi merupakan tindakan yang di tafsirkan seseorang dalam bentuk komunikasi baik itu verbal maupun non verbal.

Manusia merupakan makhluk sosial yang tidak akan pernah lepas dari bantuan sesama, baik untuk di kegiatan sehari-hari, untuk hidup berjangka panjang ataupun untuk saling mengasihi. Semua kehidupan kita di dunia tidak akan pernah terlepas dari bantuan manusia lain. Begitupun dengan menikah, menikahpun saling sama-sama membutuhkan. Kita menikah karena kita sadar sebagai makhluk sosial kita butuh teman hidup untuk saling mengasihi dan menjaga satu sama lain disamping untuk mendapatkan keturunan. Agamapun sangat menganjurkan untuk menikah, karena dengan menikah kita mendapatkan ketenangan secara batin.

Budaya tidak dapat terpisahkan dengan komunikasi, sebab pada upacara pernikahan saja contohnya terdapat banyak sekali makna dan symbol. Begitu pun pada upacara pernikahan pada adat betawi, mungkin banyak sekali orang yang menganggap budaya pada pernikahan Betawi hanyalah sebatas ondel-ondel atau palang pintu namun kenyataan aslinya banyak sekali hal-hal unik di dalam adat pernikahan betawi. Untuk mengetahui hal tersebut peneliti akan mencari tahunya dengan melakukan studi etnografi komunikasi. 
Pengertian komunikasi secara etimologis berasal dari bahas Latin, yaitu communicatio. Istilah tersebut bersumber dari perkataan communis yang berarti sama; artinya sama makna atau sama arti. Hakikat komunikasi adalah proses pernyataan pesan antar manusia dalam bentuk isi pikiran, ide, gagasan, pendapat, dan/atau perasaan seseorang kepada orang lain dengan menggunakan bahasa sebagai alat penyampai pesan (message), orang yang menyampaikan pesan disebut komunikator (communicator), sedangkan orang yang menerima pernyataan dinamakan komunikan (communicate/communicant). Faktor personal yang memperngaruhi perilaku manusia salah satunya adalah faktor sosiopsikologis. Menurut pendekatan ini proses sosial seseorang akan membentuk beberapa karakter yang akhirnya mempengaruhi perilakunya. Karakter ini terdiri dari tiga komponen yaitu komponen afektif, kognitf dan komponen konatif (Rakhmat, 2007:37).

Definisi budaya paling awal dikemukakan oleh Edward B Taylor, yang dikenal juga sebagai pendiri kajian keilmuan Antroplogi Budaya, mendefinisikan budaya sebagai "suatu sistem kompleks yang terdiri dari pengtahuan, kepecayaan, seni, moral, hukum, adat istiadat dan kapabilitas dan perilaku lain yang didapatkan manusia sebagai anggota dari masyrakat" (Mindness et al., 2006). Spencer mendefinisikan budaya sebagai bagian dari cara manusia berpikir, bertindak, merasakan, dan apa yang kita percayai. Dalam istilah sederhana, budaya dimaknai sebagai cara hidup manusia - termasuk di dalamnya meliputi sistem ide, nilai, kepercayaan, adat istiadat, bahasa yang diturunkan dari satu generasi ke generasi yang lain dan yang menopang cara hidup tertentu (Wood, 2013).

Dengan demikian, komunikasi berarti proses penyampaian pesan oleh komunikator pada komunikan dengan maksud dan tujuan tertentu. Jika dianalisis, pesan komunikasi terdiri dari dua aspek yaitu isi pesan (the content of message) dan lambang (symbol). (Mulyana:2004)

Adapun pertanyaan dalam penelitian ini, sebagai berikut: "Bagaimana bentuk perilaku komunikasi, makna komunikasi verbal dan nonverbal serta unsur asimilas dalam upacara pernikahan Betawi?"

\section{METODE PENELITIAN}

Dalam penelitian ini peneliti menggunakan paradigma konstruktivisme, yang memungkinkan peneliti untuk langsung pendekatan dengan orang-orang yang diteliti dan juga terlibat secara langsung dengan mereka. Dengan pendekatan secara langsung dan intim sehingga peneliti mampu mengonsepkan kenyataan yang sebenarnya dari sudut pandang orang-orang tersebut. Dengan menyortir bukti sebelum melakukan penafsiran terhadap kenyataan atau realitas, peneliti meyakini gagasan dari Daymond dan Halloway (2008), yang menyatakan bahwa 
teori dan konsep muncul dari data yang dihubungkan secara langsung dengan situasi tertentu yang berlangsung secara alami

Studi yang akan digunakan adalah studi etnografi komunikasi yang merupakan turunan dari ilmu etnografi. Studi etnografi komunikasi merupakan salah satu dari sekian studi penelotian kualitatif (paradigma interpretif atau konstruktivis) yang mengkhususkan pada penemuan berbagai pola komunkasi yang digunakan oleh manusia dalam suatu masyarakat tutur. Gambaran dari ilmu etnografi komunikasi adalah bahasa, komunikasi, dan kebudayaan. Definisi etnografi komunikasi itu sendiri adalah pengkajian peranan bahasa dalam perilaku komunikatif suatu masyrakat, yaitu cara-cara bagaimana bahasa dipergunakan dalam masyarakat yang berbedabeda kebudayaannya (Kuswarno:2008).

\section{HASIL PENELITIAN DAN PEMBAHASAN}

Bentuk Perilaku komunikasi merupakan suatu perilaku yang ditimbulkan oleh seseorang karena terjadinya stimulus dan respon. Akibat dari stimulus tersebut terjadilah suatu perilaku yang ditimbulkan oleh seseorang. Hubungan perilaku dengan komunikasi amatlah erat, setiap bentuk perilaku yang muncul dari seseorang pastilah menggunakan bahasa, baik verbal maupun nonverbal. Pada penelitian upacara pernikahan Betawi sangatlah banyak bentuk dari perilaku komunikasi yang pengamat amati.

\section{Buka Palang Pintu}

Palang dalam bahasa Indonesia berarti menghalangi sedangkan pintu adalah berarti tampat masuk. Palang pintu adalah upacara adat dimana pada saat mempelai laki-laki masuk ke tempat mempelai wanita, namun mempelai laki-laki tidak dapat masuk apabila belum menyelesaikan syarat dari sang mempelai wanita, biasanya terdapat dua syarat yaitu mengalahkan tukang pukul (palang pintu dari kubu mempelai wanita) dan syarat yang kedua adalah mempelai laki-laki tersebut harus bisa sikeh (dapat mengaji).

Berdasarkan hasil dialog dengan bang Rudi, selaku ketua bidang pengelolaan budaya Betawi di LKB mengatakan bahwa, “Adegan berantem main pukul sebenarnya mempunyai makna pihak pengantin pria mestis memiliki sifat berani, dapat melindungi anak bininya kelak, dan hal tersebut harus dibuktikan didepan para jawara dan keluarga pengantin wanita."

\section{Rebana Ketimpring}


Rebana pada kesenian Betawi pada dasarnya memiliki dua jenis yaitu, rebana ngarak dan rebana maulid. Sesuai namanya rebana ngarak di gunakan untuk mengarak pengantin pria memasuki kawasan mempelai wanita. Mengarak berarti mengiringi.

Hal tersebut juga dikatakan oleh bu Siti Maryam, ia menegaskan bahwa,"Kalau rebana ketimpring dipakenya buat ngarak sama maulidan, nah biasanya kalau ngarak dipake pas iringiringan mempelai laki mau kerumah cewenya dan abis palang pintu selesai baru tuh rebana di mainin".

Rebana ketimpring adalah sebuah rebana yang di pinggirnya terdapat kecrekan sehingga bunyi yang ditimbulkan tidak hanya sebuah pukulan namun kalau orang Betawi bilang terdapat ketimpringnya juga. Syair lagu yang dimainkan pada saat mengarak pengantin pria biasanya adalah sebuah shalawat. Syair shalawat tersebut diambil dari kitab maulid Syarafal Anam, Addibai, atau Diiwan Hadroh.

\section{Kembang Topeng Putri}

Tarian kembang topeng putri merupakan tarian yang dapat digunakan untuk pembukaan atau sambutan dan juga dapat digunakan untuk ucapan selamat datang pada saat pernikahan. Hal tersebut juga sesuai dengan yang dikatakan bu Yani pada saat wawancara yang dilakukan pada saat pagelaran seni budaya betawi di setu babakan yang diadakan oleh pemerintah DKI Jakarta sebagai berikut, "Tarian kembang topeng putri biasa digunakan untuk pembukaan acara atau ucapan selamat datang pas nikahan mbak".

Jawaban lain di tambahkan oleh bang Entong Kisam pada saat wawancara, ia mengatakan:

... sebenernya tari tersebut tidak menggunakan topeng namun topeng itu melambangkan organisasinya, misalkan sanggar topeng betawi ratnasari. Jadi istilah topeng itu sendiri adalah sebenarnya figurnya, zaman dahulu orang bertanya 'hei mau nopeng kemana?' jadi bukan berupa topeng benda atau kedok. Kalau topeng tunggal memiliki tiga jenis topeng dan itu memang ada artinya, topeng panji, samba, dan jingga. Jadi, satu orang penari lalu menarikan tiga karakter topeng, bukan hanya tiga karakter topeng namun juga tiga karakter manusia. Tarian topeng putri hanyalah dasar serta potongan dari tarian asilnya yang bernama kang aji, lagu yang dimainkan saat menarikan kembang topeng putri adalah lagu balo-balo.

\section{Makna Komunikasi Verbal dan Nonverbal}

Komunikasi yang terjadi di kehidupan kita sehari-hari tidak hanya dilakukan dengan komunikasi verbal melainkan juga komunikasi nonverbal, bahkan pengaruh komunikasi non verbal terkadang lebih menyentuh dari pada komunikasi verbal. Menurut Knapp dan Hall pada 
buku komunikasi lintas budaya (2006) kita tidak mungkin memisahkan perilaku verbal dan non verbal kedalam dua kategori yang berbeda dan terpisah. Hubungan komunikasi verbal dan non verbal tercermin dalam sejumlah cara.

\section{Makna Komunikasi Verbal}

Komunikasi verbal merupakan komunikasi yang menggunakan sejumlah kata-kata. Katakata verbal memiliki makna yang di pertukarkan oleh para pelaku dalam upacara pernikahan adat betawi. Berdasakan pengamatan peneliti, pemilihan kata-kata yang terjadi pada saat wawancara, pembawa acara berbicara, atraksi palang pintu, lamaran, dan sebagainya, bahwa kata yang digunakan bukanlah bahasa Indonesia baku ataupun formal. Hal tersebut terbukti dari wawancara berikut dengan Bang Rudi:

Bahasa yang digunakan ya emang khas Betawi bukan bahasa Indonesia, kalau bahasa Indonesia berarti gak ada khasnya yang nyentrik neng. Kalo bahasa orang Betawi emang jarang yang ngikut bahasa Indonesia, semua emang udah kebawa dari lingkungan juga apalagi orang Betawi asli, itu mah pasti sehari-hari lebih banyak kata Betawi dari pada bahasa Indonesia yang bener.

Berdasarkan pengamatan yang dilakukan peneliti memang terlihat sangat jelas, bahwa bahasa yang digunakan pada saat upacara pernikahan Betawi sangat kental dengan kosakata Betawi, hal tersebut terlihat jelas pada pembawa acara, pemain palang pintu, orang tua mempelai, dan saudara-saudara sang pengantin.

Hasil penemuan dan pengamatan peneliti dalam komunikasi verbal adalah, sebagai berikut:

Tabel 1

\begin{tabular}{ll}
\hline Bahasa Betawi & Bahasa Indonesia \\
\hline Daon & Daun \\
\hline Duduk nike & Ijab kabul di depan penghulu \\
\hline Geplak & Kue dari sagu \\
\hline Kelape & Kelapa \\
\hline Kenape & Kenapa \\
\hline Kuatir & Khawatir \\
\hline Kudu bias & Harus bisa \\
\hline Maen & Main \\
\hline Mang ngape & Emang kenapa \\
\hline Muare & Muare \\
\hline Pepe & Kue lapis \\
\hline Pulo & Pulau \\
\hline Saye & Saya \\
\hline Sikeh & Bisa mengaji \\
\hline
\end{tabular}




\section{Sumber: Olahan peneliti}

\section{Makna Komunikasi Nonverbal}

Komunikasi nonverbal merupakan pelengkap dari komunikasi verbal, dengan adanya komunikasi nonverbal yang ditimbulkan dalam berkomunikasi membuat pesan yang di sampaikan lebih jelas dan kuat dalam penegasannya. Komunikasi nonverbal pada upacara pernikahan betawi meliputi, diantaranya, ekspresi wajah, gerakan tubuh, nada suara, dan busana.

\section{a. Pakaian atau Busana}

Sepenglihatan peneliti dalam acara upacara pernikahan betawi, pakaian yang digunakan para keluarga, pengantin, dan pengisi acara sangat menunjukan tradisi Betawi-nya dan meyimbolkan bahwa mereka orang Betawi, hal itu terlihat dari seragam keluarga yang menggunakan celana joger namun terdapat aksen sarung pada bagian tengah antara pinggang hingga paha serta yang perempuannya menggunakan kaftan. Hal yang lebih menguatkan bahwa mereka keluarga betawi pada saat memasuki pelataran gedung, disambut oleh penerima tamu yang menggunakan kebaya betawi serta pengantin perempuan yang menggunakan cadar dan konde Betawi dan pengantin laki-laki menggunakan baju adat Betawi dengan terdapat aksen batik Betawi di bagian sarong- nya

\section{b. Gerakan}

Pada saat terjadi ijab qabul, peneliti melihat banyak sekali gerakan yang mendukung komunikasi verbal, mulai dari begitu eratnya pelukan sang ayah yang akan melepas anak terakhirnya pergi dan terlihat sangat sedih serta hal-hal kecil lainnya.

\section{c. Nada Suara}

Pada saat pernikahan berlangsung, nada yang digunakan juga sesuai dengan momen yang dilakukan. Contohnya, pada saat ijab qobul dilaksanakan maka pembawa acara membawakan acara dengan tenang dan sakral, lalu pada saat palang pintu saling bersahutan pantun maka ada nada yang tinggal untuk mengaplikasikan bahwa sang jawara dari pengantin pria di tantang untuk berkelahi agar bisa mendapatkan pengantin wanita.

\section{d. Kecepatan dalam berbicara}

Kecepatan nada dalam berbicara sangat terlihat jelas pada saat peneliti memperhatikan sang pengantin pria, Mas Deni yang pada saat mengucapkan ijab qobul terlihat sangat cepat-cepat mengucapkan kalimat tersebut di karenakan rasa tegang dan gerogi.

\section{e. Kontak mata}


Komunikasi nonverbal selanjutnya yaitu adalah kontak mata, kontak mata yang intens serta keseriusan dalam melihat dan memperhatikan lawan bicara kita merupakan tanda keseriusan mendengarkan dan memahami apa yang dikatakan oleh lawan bicara kita. Pada saat ijab qobul selesai, mas Deni dan Mbak Nia mendapatkan wejangan pernikahan dari seorang ustad, dan mereka terlihat sangat serius untuk mendengarkan dan melihat ke sang pemberi wejangan dengan intens.

\section{Unsur Asimilasi}

Asilimasi adalah apabila terdapat sekumpulan orang yang berkumpul dengan intens dalam kurun waktu yang lama namun dengan latar belakang kebudayaan yang berbeda, sehingga kebudayaan-kebudayaan dengan golongan-golongan tadi berubah sifatnya yang khas dan juga unsur masing-masing berubah menjadi unsur kebudayaan campuran.

Budaya betawi merupakan budaya yang mestizo, yaitu terdapat campuran dari kebudayaan lainnya namun memiliki sifat yang berbeda. Hal ini terlihat jelas pada:

\section{a. Aksesori pengantin wanita}

Pada ornamen pengantin wanita terdapat unsur dari kebudayaan lain yaitu Cina, dimana pada sanggul konde tersebut terdapat beberapa jenis tusukan konde, di antaranya:

1. Tusuk paku ini berbentuk sekitar $5 \mathrm{~cm}$ dan berbentuk bunga kecil, sebagai tanda penolak bala.

2. Tusuk bunga 5 buah, dimana tusuk bunga tersebut melambangkan bahwa rukun Islam adalah 5.

3. Tusuk kembang rumput 20 buah, melambangkan untuk menyimbolkan bahwa terdapat 20 sifat Allah.

4. Tusuk burung hong 4 buah yang melambangkan bahwa sahabat dari Nabi Muhammad adalah 4 orang.

Selain konde yaitu terdapat cadar atau siangko, dimana cadar tersebut melambangkan kesucian dari sang wanita dan warna emasnya melambangkan dari wanita tersebut berasal dari kalangan menengah atas. Lalu terdapat tusuk Lam (abjad Arab) pada sanggul konde pengantin perempuan, dan keduanya, cadar dan tusuk lam merupakan budaya yang dibawakan oleh bangsa Arab dan diadopsi pada kebudayaan Betawi.

\section{b. Unsur alat musik}

Alat musik yang digunakan pada kebudayan betawi sangatlah beragam, namun banyak alat musik yang sebenarnya diadopsi dari budaya Cina seperti tehyan, Tehyan berasal dari Cina yang pada saat itu dibawa oleh etnis Tionghoa sewaktu menetap di Batavia. Tehyan 
adalah alat musik yang cara permainannya digesekan, terdapat 3 jenis Tehyan yaitu Sukong, Tehyan, dan Kong Ahyan.

\section{c. Unsur makanan}

Pada saat wawancara dengan bang Rudi, ia menjelaskan bahwa banyak sekali makanan yang memang adanya pengaruh dari luar, dalam kutipan wawancara dengan bang Rudi:

"Kalo unsur budaya lain banyak emang, kalo dipakean Betawi ditusukan konde itu unsur dari budaya Cina, kalo cadar dari Arab, musik juga ada kaya teyan itu dari Cina juga, malah makanan juga ada unsur dari budaya luarnya kaya Cina, Arab, Portugis” Pengaruh Cina: Contoh makanan yang diadaptasi dari Tiongkok itu adalah bakso. Bakso adalah makanan dari cina, kata Bak berarti daging babi dan So adalah bulat, maka bakso adalah daging bulat namun karena Indonesia mayoritas muslim, maka penggunaan untuk daging bakso adalah ayam atau sapi. Bihun dan tahu juga merupakan makanan yang berasal dari Cina, bahkan makanan ini menjadi bahan pokok dalam makanan khas Betawi seperti ketoprak, tauge goreng, asinan betawi, dan soto mie. Pengaruh Belanda: Pada dasarnya tidak banyak pengaruh makanan dari Belanda, hanya saja ternyata makanan yang kita kenal selama ini dengan semur merupakan kosakata bahasa Belanda yang di ambil dari smoor, yang artinya dimasak dengan api kecil. Pengaruh Portugis: Pada saat zaman dahulu, banyak pedagang Portugis yang melabuhkan kapal mereka di Batavia dan beberapa cara masak orang portugis di adapsi oleh masyarakat Betawi yaitu ciri khas dengan bumbubumbu yang dibakar kalau dalam masakan Betawi, kita dapat menemukan masakan yang bernama pindang serani, makanan ini cara memasaknya adalah semua bumbunya dibakar. Sekarang komunitas keturunan Portugis masih dapat kita temui di daerah Kampung Tugu, Jakarta Utara. Pengaruh India: Pengaruh dari India di bawa oleh para pedagang Kerala yang memang mereka di negaranya terkenal dengan juru masak handal. Kari adalah salah satu makanan yang diperkenalkan para pedagang India ke Indonesia, namun kalau untuk betawi, pengaruhnya adalah santan. Santan adalah bahan pokok untuk membuat nasi uduk betawi. Pengaruh Arab: Masakan betawi yang mengadaptasi dari negeri Timur Tengah ini adalah soto tangkar, acar, nasi kebuli. Masakan yang berasal dari Timur Tengah ini terkenal sekali dengan bumbu minyak samin, kapulaga, dan jinten.

\section{SIMPULAN}


Bentuk dari perilaku komunikasi pada upacara pernikahan Betawi diantaranya adalah pengarakan menggunakan rebana ketimpring serta membaca shalawat sebelum masuk ke tempat kediaman mempelai wanita, pembacaan saritilawah yang wajib dilaksanakan pada setiap pernikahan Betawi, adanya atraksi bukaan palang pintu sebelum mempelai pria memasuki kawasan resepsi. Namun, ada beberapa hal budaya yang memang tidak bisa dipenuhi seperti petasan sebagai ikon dari sebuah pernikahan Betawi namun pada saat pernikahan Mas Deni dan Mbak Nia berlangsung mereka tidak menggunakan petasan di karenakan tempat yang mereka jadikan resepsi tidak mengizinkan membunyikan petasan dan mereka tidak menggunakan tarian topeng yang menjadi ciri khas dari Betawi karena mereka merasa dengan adanya palang pintu sudah cukup memberikan simbol bahwa mereka adalah orang Betawi, jadi anggaran untuk hiburan tarian memang tidak ada. Dari tujuh proses pernikahan pada tradisi Betawi yang di antaranya ngedelengin, ngelamar, bawa tande putus, akad nikah, kebesaran, negor dan pulang tige ari, yang paling umum digunakan di zaman sekarang hanya ngelamar, bawa tande putus dan kebesaran, sisanya sudah sangat jarang dan tidak diaplikasikan lagi oleh banyak orang hal ini dikarenakan perkembangan zaman yang semakin modern membuat orang yang membuat acara pernikahan hanya melihat acara inti seperti lamaran, bawe tande putus (tunangan), dan besaran (resepsi).

Makna komunikas verbal dan nonverbal pada upacara pernikahan Betawi adalah bahasa yang kental Betawi masih sangat terdengar jelas di antara mayoritas undangan dan keluarga pengantin serta para pelakon dalam upacara tersebut yang menggunakan bahasa Betawi seperti duduk nike, maen, penganten, gue, iye, di mari, dll. Makna komunikasi nonverbal dapat dilihat dari baju seragam yang digunakan, gerakkan, nada suara, serta kontak mata.

Unsur asimilasi dalam upacara pernikahan Betawi terlihat dari tusukkan konde yang digunakan oleh sang pengantin wanita merupakan asimilasi dari budaya Cina, yaitu terdapat tusukkan konde berbentuk burung Hong serta terdapat unsur asimilasi dari budaya Arab, yaitu tusukkan konde yang di beri nama tusukkan lam (bahasa Arab) dan cadar. Alat musik serta makanan pun memiliki unsur asimilasi dari negara lain di antaranya Cina, Portugis, India, Belanda, dan Arab.

\section{DAFTAR PUSTAKA}


Buku:

Kuswarno, Engkus. (2009). Fenomenologi: Metodologi Penelitian Komunikasi. Bandung: Widya Padjadjaran

Knapp, Mark L dan Judith A. Hall. (2006). Nonverbal Communication in Human Interaction, Sixth Edition. USA : Thomson Wadsworth.

Daymon, Christine., dan Immy Holloway. (2008). Metode-metode Riset Kualitatif: dalam Public Relations dan Marketing Communications. Yogyakarta: Penerbit Bentang.

Mulyana, D. (2004). Ilmu Komunikasi, Suatu Pengantar. Bandung: PT. Remaja Rosdakarya Mindess, Sidney et al. (2003)., “CONCRETE 2ND EDITION”. Pearson Education, Inc. USA Rahkmat, Jalaluddin. 2008, Psikologi Komunikasi. Bandung: PT. Remaja Rosdakarya

Wood Julia. (2013), Komunikasi Interpersonal: Interaksi Keseharian. Jakarta: Salemba Humanika

\section{Jurnal:}

Putra, A (2015), Studi Fenomenologi Ta'aruf Sebagai Cara Menentukan Pasangan Hidup Pada Partai Keadilan Sejahtera. Jurnal Ilmiah LISKI (Lingkar Studi Komunikasi), [Online] 209223. Available from: http://journals.telkomuniversity.ac.id/liski/article/ view/823/613.

\section{Artikel Internet:}

Liputan6.com (2018) https://www.liputan6.com/regional/read/3620412/berapa-jumlah-baha-sadaerah-di-indonesia-saat-ini.

\section{Skripsi, Tesis, Disertasi:}

Dewi, I Gusti Ayu. 2015. Aktivitas Komunikasi Upacara Pernikahan Suku Sasak (Studi Etnografi Komunikasi Dalam Upacara Kawin Culik Di Desa Rembitan, Lombok Tengah) Skripsi. Universitas Telkom, Bandung, Indonesia. 